\title{
US panel rejects calls for warning labels on link between food dyes and hyperactivity
}

$\mathrm{U}$ nited States regulators are taking a closer look at the dyes that create those eye-catching colours in Froot Loops, Skittles and orange Fanta to determine if the artificial colourings contribute to hyperactive behaviour in some children.

Further study is needed on whether consuming artificial dyes can negatively affect children's behaviour, a federal advisory panel indicated after two days of hearings on the issue, while narrowly rejecting calls for food labels that warn about a potential link between hyperactivity and synthetic dyes.

The US Food and Drug Administration began its review of the issue after the private Center for Science in the Public Interest (CSPI) in 2008 filed a petition asking the government to ban the use of synthetic dyes and, in the interim, require food warning labels about their impact on the behaviour of some children. The center said a number of scientific studies had shown that synthetic dyes may exacerbate behaviour problems in some children.

In response to specific questions posed by the FDA, the agency's food advisory committee voted $13-1$ for more research on the subject and 8-6

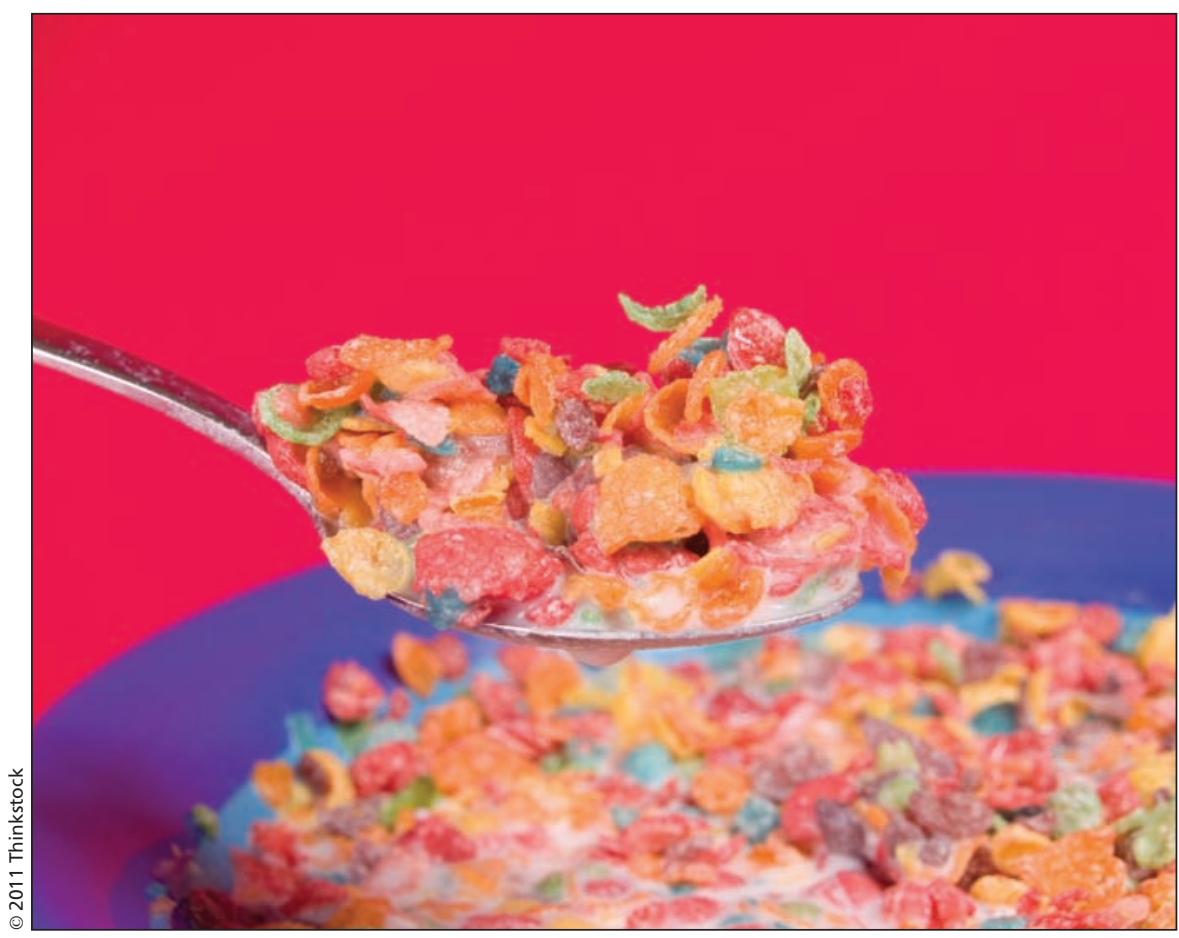

A United States Food and Drug Administration committee of physicians, food experts, scientists and consumers concluded there is no causal relationship between consumption of colourful food dyes and hyperactivity in children.

tee's recommendations under consideration as it continues its review of the issue. No decision is imminent.

CSPI Executive Director Michael

\section{"I don't need to have more studies," says Renee Shutters. "All I need is a bag of M\&M's and 10 minutes."}

against new warning labels. It agreed that some children may benefit from diets that eliminate synthetic dyes, but said a "causal relationship between consumption of certified color additives in food and hyperactivity in children in the general population has not been established." The committee is made up of doctors, food experts, scientists and consumer representatives.

FDA spokesman Douglas Karas says the agency will take the commit-
Jacobson says he's disappointed that the committee didn't support warning labels. But he was encouraged that the government is at least looking into the link between food dyes and children's behaviour. "A year ago, the agency maintained that there was no evidence that dyes affect children's behaviour," he says. "Now, the agency recognizes that dyes do affect some children."

One of those children is seven-yearold Trenton Shutters of Jamestown,
New York. His mother testified before the advisory committee about startling improvement in her son's behaviour once she cut out food dyes.

"His behaviour kept getting better and better," Renee Shutters says, adding that she feels lucky that the family was able to make the connection. "If we hadn't figured this out, I'm afraid to even think about where we would've been."

Parents of other children need to be warned about the possible connection, she says, so they "don't just think they have a difficult kid."

Sean Taylor, scientific director of the International Association of Color Manufacturers, says there may be "a small subpopulation with some sort of unique intolerance" for colour additives. As for labelling, Taylor says consumers already have good information about what dyes are in their food, thanks to 
package labels, and can make their own choices about what products to avoid.

CSPI cautions that artificial dyes aren't just present in a few colourful junk foods marketed to kids - they're in pickles, instant mashed potatoes and a broad range of processed US foods.

Jacobson said in a statement that in Europe, by contrast, a law requires most dyed foods to bear a warning label (www.cspinet.org/new/201103301.html). As a result, manufacturers use more natural dyes there. "Last I heard, Europe is surviving quite well. It is to the great shame of many U.S.-based food companies that they are marketing safer, naturally coloured products in Europe but not in the United States."

The Washington, DC-based Grocery Manufacturers Association stressed in a statement that artificial colours have been reviewed by the FDA and deemed safe (www.gmaonline.org/news-events /newsroom/grocery-manufacturers-assoc iation-comments-on-safety-of-artificial -colors/).
But Shutters shops at stores that import goods from Europe to get candy and other foods made with natural colourings. She rejects the arguments of those who say the link between dyes and hyperactivity is an urban legend.

"I don't need to have more studies," she says. "All I need is a bag of M\&M's and 10 minutes." - Nancy Benac, Washington, DC

CMAJ 2011. DOI:10.1503/cmaj.109-3867 